\title{
Os limites do conceito de empoderamento na prevenção ao HIV/Aids entre jovens gays e bissexuais no Brasil
}

| ${ }^{1}$ Luiz Felipe Zago, ${ }^{2}$ Luís Henrique Sacchi dos Santos |

Resumo: O artigo objetiva realizar uma análise teórica dos limites do conceito de empowerment inserido em uma política de prevenção ao HIV/Aids entre jovens gays e bissexuais no Brasil. Parte de proposiçôes de um documento oficial do Ministério da Saúde do Brasil, cuja forma é de um manual metodológico, que coloca o empowerment como conceito central na execução da prevenção para essa população. A análise utiliza-se do arcabouço teórico pós-estruturalista para examinar os modos como o conceito é descrito e operacionalizado nas atividades sugeridas pelo manual. Indica-se que o empowerment é uma estratégia de governamento dos corpos e das autonomias dos indivíduos que funciona dentro de uma racionalidade ampla de controle, constituindo-se em uma tecnologia de regulação das práticas sexuais e medição calculável das subjetividades. Exploram-se as noções de risco e responsabilização que circunscrevem a comunidade de jovens gays e bissexuais à qual a prevenção se dirige. Como conclusão, sublinham-se os impasses que a introdução desse conceito pode gerar no campo da resposta brasileira à epidemia de HIV/Aids, sem que seja feita uma revisão crítica dos modos como ele é concebido e implementado.

> Palavras chave: HIVIAids; poder; promoção da saúde; prática de saúde pública.

\author{
1 Doutor em Educação pela \\ Universidade Federal do \\ Rio Grande do Sul (UFRGS), \\ Porto Alegre, Brasil. Endereço \\ eletrônico: luizfelipezago@ \\ gmail.com \\ ${ }^{2}$ Doutor em Educação; \\ professor adjunto no \\ Departamento de Ensino e \\ Currículo da Faculdade de \\ Educação da UFRGS, Porto \\ Alegre, Brasil. Endereço \\ eletrônico: luishss2009@ \\ gmail.com
}


Este artigo $^{1}$ é uma análise dos limites do conceito de empowerment como norteador de práticas de prevenção ao HIV/Aids entre jovens gays no Brasil. Tal análise toma como base um documento oficial do Ministério da Saúde, o DEBI Brasil MPOWERMENT Estratégia de Prevenção para as DST-HIV (BRASIL, 2011), que contempla a definição do referido conceito e provê elementos para sua operacionalização, assumindo o formato de manual. Parte para a reflexão conceitual sobre a implementação do empowerment como guia de ações de prevenção ao HIV/Aids por parte de profissionais da saúde e integrantes de organizações não governamentais.

Adota-se a perspectiva pós-estruturalista, apoiando-se no conceito de governamento (FOUCAULT, 1995; 1984), reapropriado e aprofundado especialmente por Rose e Miller (2008), Rose (1999), Lupton (1995, 1999) e Lupton e Tulloch (2003). Propõem-se análises que examinam o empowerment como uma peça de uma engrenagem ampla de regulação dos corpos, exercendo o governamento dos sujeitos através da constituição de autonomias controladas. Exploram-se as noções de risco e responsabilização que circunscrevem a comunidade de jovens gays e bissexuais à qual a prevenção se dirige. Por fim, sublinham-se os impasses que a introdução desse conceito, do modo como prescrito no referido documento, pode gerar no campo da resposta brasileira à epidemia de HIV/Aids.

Recentemente, crescem os dados epidemiológicos e resultados de pesquisas disponíveis sobre a epidemia de Aids que subscrevem a necessidade de ações de prevenção entre a população de jovens homens que fazem sexo com homens (HSH), gays e bissexuais (BELOQUI, 2008; SZWARCWALD et al., 2011; MARQUES JR et al., 2012). O Ministério da Saúde, através do Departamento Nacional de DST, AIDS e Hepatites Virais, vem investindo em projetos voltados para essa população - como o Saúde e Prevenção nas Escolas (SPE) -, sobretudo em "metodologias de prevenção das DST/HIV para gays e outros HSH que tiveram êxito comprovado", ou seja, que tenham "sua eficácia cientificamente comprovada" de modo que sejam passíveis de "serem avaliadas, monitoradas e transformadas em metodologias replicáveis por outras organizaçôes” (BRASIL, 2011, p. 5). Ressaltase a existência do Plano Nacional de Enfrentamento à Epidemia de Aids entre Gays, HSH e Travestis (BRASIL, 2007), iniciativa que procura articular as três esferas de governo, mais os movimentos sociais, para a promoção de saúde, Direitos Humanos e prevenção para esse grupo específico da população. 
Segundo Parker (2004), pelo menos desde o início da década de 90 implementaram-se diversas estratégias preventivas entre gays e HSH no Brasil. Baseando-se na retomada dos projetos executados pela Associação Brasileira Interdisciplinar de Aids (ABIA-RJ), o autor menciona que as intervenções da década de 90 caracterizaram-se por pesquisas comportamentais e etnográficas especificamente voltadas para HSH e gays; já nos anos 2000, a prevenção foca a parcela de jovens homossexuais. O importante da retrospectiva que Parker apresenta é a ênfase na ampliação social e programática que a prevenção ao HIV/Aids entre HSH e gays ganhou nos anos 2000: o reconhecimento de que metodologias de prevenção levassem em conta a cultura e a política dentro das quais as estratégias preventivas fossem implementadas (PARKER, 2004).

Nessa direção, Ayres e seus colaboradores (2000) mencionam que o conceito de grupo de risco, e, mais tarde, o de comportamento de risco, marcaram os primeiros anos da resposta a epidemia de HIV/Aids. Os autores sinalizam que a resposta brasileira organizou-se no sentido de construir e consolidar o conceito de vulnerabilidade social em detrimento daqueles, precisamente porque o conceito de vulnerabilidade social se articula com o paradigma dos Direitos Humanos e desinveste as práticas de prevenção como sendo atitudes meramente individuais (PAIVA, 2009; MEYER et al., 2006; AYRES et al., 2000). Isso fez com que as diferentes estratégias desenvolvidas no país tivessem a tradição de um olhar amplo, cultural, social e político na promoção da saúde e na prevenção, reforçando o exercício de cidadania de grupos historicamente marginalizados, em consonância com o marco dos Direitos Humanos (PARKER, 2004).

É nesse contexto que se insere a metodologia MPowerment, sobre a qual versa o Manual disponibilizado na página do Departamento Nacional. O nome MPowerment deriva de empowerment, e a letra $M$ designa especificamente "homens" (men, em inglês). Trata-se de um conjunto de açôes importadas do contexto estadunidense voltadas para o empowerment de homens frente à epidemia de HIV/Aids. O MPowerment faz parte de um portfólio de metodologias que compõem a Diffusion of Effective Behavorial Interventions - HIV Preventions That Work ${ }^{2}$ (DEBI), financiadas pelo Centers for Disease Control and Prevention (CDC) - HIVIAIDS Division ${ }^{3}$ no contexto dos Estados Unidos. A introdução dessas metodologias no Brasil faz parte de uma cooperação internacional entre os dois países ${ }^{4}$. 
Nesse âmbito, a metodologia MPowerment é concebida como um conjunto de açôes baseadas em evidências (evidence-based) sobre os condicionantes de saúde do grupo a que se destina, sendo dirigida para comunidades específicas (community-based). O empowerment é não apenas um conceito norteador, mas, como o próprio manual diz, versa sobre uma estratégia ampla e complexa de intervenção, monitoramento e avaliação de ações de promoção da saúde. A prevenção ao HIV/Aids como ação calculável, mensurável e passível de apreensão estatística para aferição de seu sucesso ou falha é característica central para a metodologia MPowerment, conforme argumentaremos na exposição detalhada de como suas ações são prescritas pelo manual.

No Brasil, uma parceria entre o Ministério da Saúde, a Escola Nacional de Saúde Pública Sérgio Arouca (ENSP/Fiocruz) e o CDC propiciou a execução de três projetos-piloto para a introdução de três diferentes metodologias de prevenção ao HIV/Aids entre jovens gays e bissexuais ${ }^{5}$. Três ONGs foram selecionadas pela Fiocruz para executar cada uma das metodologias em três capitais brasileiras. Além do MPowerment, cujo piloto foi executado em Porto Alegre, também experimentaram-se a metodologia Many Men, Many Voices, no Rio de Janeiro, e a Popular Opinion Leader, em Fortaleza - cada uma delas com um manual específico. O período de execução dos projetos-piloto se deu ao longo de 2011. As metodologias deveriam ser executadas seguindo passo a passo as orientações contidas nos respectivos manuais.

\section{Quem precisa de empowerment?}

Segundo Lupton (1995, p. 89), empowerment é um dos núcleos filosóficos do movimento da Nova Promoção da Saúde, sobretudo após a sistematização de suas linhas de ação amplas através da Carta de Ottawa, produzida durante a $1^{a}$ Conferência Internacional de Promoção da Saúde, em 1986. Sua tradução para o português é controversa, o que faz com que sua menção seja muitas vezes mantida em inglês (FERREIRA; CASTIEL, 2009; CARVALHO, 2008; BECKER et al., 2004). Outros autores, no entanto, utilizam-se do termo "empoderamento" para designar empowerment, principalmente para descrever pesquisas no campo da saúde pública (MARTINS et al., 2009; LEFÉVRE; LEFÉVRE, 2004).

Embora não tenhamos o objetivo de realizar uma revisão bibliográfica sobre o uso do conceito no campo da saúde pública, é importante mencionar que em 
outros países ele é central para a intervenção em determinados grupos sociais no sentido de reverter os processos de dominação social que produzem dificuldades para a promoção da saúde (RIFKIN, 2003; LAVERACK; WALLERSTEIN, 2001; LAVERACK; LABONTE, 2000). Por exemplo, Myrick (1996) reflete sobre empowerment relacionando-o à identidade gay e à comunicação de mensagens de saúde pública sobre Aids; Kegeles ${ }^{6}$ (1996) mostra que homens afrodescendentes e latinos dos Estados Unidos são os grupos principais nos quais o empowerment é utilizado como metodologia na prevenção ao HIV/Aids.

Neste artigo, escolhemos traduzir empowerment como empoderamento porque assim podemos explorar teoricamente a articulação desse conceito com as relações de poder no seio das teorizações pós-estruturalistas, bem como as implicações da sua operacionalização no contexto brasileiro de prevenção ao HIV/Aids. Assim, buscamos demonstrar na sua dinâmica de funcionamento como se operacionaliza a produção de poder onde ele supostamente não existe, como a palavra em português sugere.

Então, quem precisa de empoderamento? Teoricamente, aqueles indivíduos e grupos sociais em situação de desigualdade frente a outros em relação ao acesso à saúde. Nesse contexto, a promoção da saúde é "o processo de capacitação (enabling) de indivíduos e coletivos (communities) para que tenham controle sobre os determinantes de saúde com o objetivo de terem uma melhor qualidade de vida". Nele, objetivam-se "mudanças no modo de vida e, também, nas condições de vida [...] combinando escolhas pessoais com responsabilidade social com o objetivo de criar um futuro mais saudável” (CARVALHO, 2004b, p. 671).

Tal noção se expressa na definição de "empowerment comunitário" (CARVALHO, 2004a, p. 1091). Ela surge para se opor ao "empowerment psicológico", que estaria focado apenas na autoestima individual a ser empoderada, não contemplando um aumento efetivo de poder nem levando em consideração os contextos sociais, culturais e políticos nos quais os indivíduos estão imersos. O "empowerment comunitário" é teorizado como um "continuum que ocorre desde o nível do individual ao macro, passando pela intermediação de coletivos e grupamentos sociais" (CARVALHO, 2004a, p. 1092).

De acordo com o manual do MPowerment, pode-se dizer que essa metodologia versa sobre "empoderamento comunitário". Aqui, o conceito está diretamente ligado à afirmação das identidades gay e bissexual entre jovens de 
18 a 30 anos e na construção de uma comunidade baseada nessas identidades. O manual da metodologia enfatiza quatro princípios norteadores: a) vida social e autoestima, em que vida social refere-se a "encontrar e se divertir com outros jovens gays/bissexuais" (BRASIL, 2011, p. 26); b) influência dos pares, em que "os pares são fonte de informações mais confiáveis" e que "a 'pressão dos pares' é uma das formas mais eficazes de influência” (p. 26); c) construção de uma comunidade saudável, dentro da qual se pretende criar "ambientes nos quais os jovens podem expressar suas identidades entre si, encontrar apoio, e unir-se para agir em relação a questões que são importantes para eles", enfatizando-se que tal organização "tem um impacto positivo sobre a saúde da comunidade" (p. 27); e, finalmente, d) o "empoderamento" como promotor de mudanças duradouras na comunidade, que objetiva fazer com os jovens estejam "ativamente envolvidos em achar soluções para seus problemas", promovendo, assim, "um sentimento de compromisso pessoal para com a prevenção ao HIV" (p. 27).

Busca-se, assim, fortalecer laços sociais e afetivos através da positivação de sentidos ligados à homossexualidade e ao sexo. Todas as atividades propostas pelo manual, que podem incluir desde uma sessão de cinema na casa de um dos jovens participantes, uma dramatização sobre uma situação de risco de infecção pelo HIV, até uma grande festa em uma casa noturna da cidade, devem contemplar a reunião do maior número possível de jovens gays e bissexuais. Isso porque entre as ambiçôes centrais dessa metodologia estão “(...) que quase todos os jovens gays/bissexuais da comunidade sejam alcançados por meio de pelo menos uma das atividades do Projeto" (BRASIL, 2011, p. 34), ou que se promova "um amplo leque de atividades de divulgação [do projeto] concebidas para agradar cada segmento da comunidade de jovens gays/bissexuais" (p. 30). O objetivo final é claro: estabelecer "um processo de mobilização comunitária capaz de se renovar de forma contínua, e que inicia um processo de difusão que sempre está se ampliando", através do qual "os jovens gays/bissexuais comunicam entre si sobre a redução do risco de infecção pelo HIV" (p. 34).

Esse conjunto de intervençôes vem densamente articulado à ideia de autonomia, indicando que os próprios jovens planejem e promovam atividades para a comunidade de que fazem parte, pensando coletivamente a demanda, as estratégias de divulgação das atividades e dividindo responsabilidades relacionadas à organização das tarefas. Nesse aspecto, é fundamental o papel 
que o fortalecimento do processo de identificação com a comunidade tem na

promoção de saúde. A virada fundamental que a metodologia propõe em relação a outras é estimular a própria comunidade de jovens gays e bissexuais para pensar e sustentar intervenções junto ao Estado e com o Estado - e para si própria.

Portanto, depreende-se que empoderamento não é apenas um conceito, mas um conceito-estratégia que funciona como prática inerente a uma determinada tecnologia de promoção da saúde e a uma racionalidade teórico-política particular. É uma ferramenta de ação que se dirige a grupos historicamente posicionados como dominados, no sentido de intervir nas condições que possibilitam tal dominação para mudar o status quo estabelecido (CARVALHO, 2008; 2004a; 2004b).

No entanto, os pressupostos nos quais a metodologia de prevenção se baseia precisam ser analisados criticamente para que se compreenda sua operacionalização e se reflita sobre as possibilidades de sua inserção no contexto da resposta brasileira à epidemia de HIV/Aids. Para isso, tal como o conceito de empoderamento é concebido na metodologia MPowerment, é necessário examinar que relações ele mantém com certos modos contemporâneos de regulação política e governamento dos indivíduos.

\section{"Empoderar" é governar}

O primeiro parágrafo da introdução do manual define a metodologia através da qual o empoderamento será produzido e indica os benefícios da sua implementação:

O Projeto MPowerment (empoderamento) foi desenvolvido para e por homens jovens gays e bissexuais. Ele mobiliza jovens gays/bissexuais para formar comunidades saudáveis voltadas para eles mesmos, construindo vínculos sociais positivos e favorecendo a prática do sexo mais seguro. O Projeto MPowerment é capaz de alcançar um quantitativo grande de jovens gays/bissexuais com um custo-benefício vantajoso porque atua em comunidades em vez de trabalhar com indivíduos ou grupos pequenos (BRASIL, 2011, p. 13).

Segundo Miller e Rose (2008) e Lupton (1995; 1999), a criação de comunidades saudáveis, como a mencionada pelo manual, faz parte de um processo contemporâneo de governamento dos indivíduos e de regulação dos seus corpos. O campo da saúde pública faz parte dessa regulação ativamente: as comunidades emergem como "o novo território para a administração da existência individual e coletiva, um novo plano ou superfície sobre o qual 
relações micromorais são conceitualizadas e administradas" (MILLER; ROSE, 2008 , p. 88)7. A formação de tais comunidades está ligada à emergência do conceito de "risco", que "pode ser visto como integrante de um entendimento racionalista da realidade, na qual eventos de infortúnio são colocados como predizíveis e evitáveis"; nesse sentido, "[o] discurso do risco é uma tentativa de domar a incerteza" (LUPTON, 1999, p. 77-78).

Rose e Miller derivam o conceito de "governamento" daquele originalmente formulado por Foucault, que designa a "condução da conduta do outro" (FOUCAULT, 2010, p. 244). Propõem que "governamento" aludeà multiplicidade de "forças e grupos que têm procurado, de modos heterogêneos, regular as vidas dos indivíduos e as condições dentro de territórios nacionais particulares na busca de vários objetivos", salientando que o conceito assinala "uma diversidade de poderes e saberes implicados em tornar campos [da realidade] exequíveis e submissos à intervenção" (MILLER; ROSE, 2008, p. 27).

Miller e Rose (2008) e Lupton (1995) dão exemplos de comunidades responsáveis que, através da sua organização política e sua autoidentificação, passam a regular-se mutuamente e a reivindicar direitos enquanto tais: "usuários de drogas, homens gays, portadores de determinados genes [...] pessoas idosas, pessoas com deficiência física ou mental” (MILLER; ROSE, 2008, p. 88-90), "pessoas com obesidade, fumantes, alcoólicos, pessoas com diabetes e problemas de pressão alta" (LUPTON, 1995, p. 59-60). Nas obras citadas, a epidemia de HIV/Aids é reiteradamente citada como emblemática para teorizações sobre risco e formação de comunidades responsáveis.

Não se trata, porém, da mera reativação da noção de grupo de risco, que marcou os primeiros anos da epidemia de Aids (AYRES et al., 2000). A diferença é sutil, porém importante: "[a] través de esforços intermináveis, o risco é problematizado, feito calculável, governável” (LUPTON, 1999, p. 87). Uma vez calculado o risco de uma comunidade, seus integrantes precisam tomar consciência dele, tomá-lo como verdade e, a partir dele, precisam intervir nas suas próprias vidas e nas vidas de outros para que o risco seja evitado. É precisamente através desse esforço que “grupos sociais particulares ou populações são identificadas como 'em risco' ou 'de alto risco', requerendo formas particulares de conhecimento e intervençôes" (LUPTON, 1999, p. 87). Tornam-se, assim, comunidades responsáveis pela sua própria regulação em relação ao risco, e não mais dependentes de um Estado que 
o faça em seu lugar. Comunidades e indivíduos responsáveis são aqueles que se gerem a si próprios, não graças ao Estado, mas no lugar dele.

Conforme aponta pesquisa feita por Tulloch e Lupton (2003), homens gays de várias geraçôes tendem a falar de risco em suas narrativas de experiências pessoais e sexuais de uma maneira mais reincidente que outros grupos. Historicamente constituída como uma comunidade para a qual se voltaram, e ainda se voltam, inúmeros esforços de prevenção ao HIV/Aids, a comunidade de homens gays é caracterizada como "em risco" tanto pelo "risco de infecção" quanto pelo "risco à violência, discriminação e ostracismo" (TULLOCH; LUPTON, 2003, p. 22), originados pela orientação sexual não heterossexual. Nesses aspectos, "risco" caracteriza uma ameaça, um espectro de incerteza e insegurança que constrange as possibilidades de experiências e circunscreve pelo medo as vidas de pessoas não heterossexuais.

Duas noções de risco são amalgamadas no seio da metodologia MPowerment: de infecção pelo HIV e de discriminação. O manual prevê a criação de um espaço onde os jovens gays e bissexuais possam se encontrar semanalmente, que incentive o fortalecimento da comunidade e que seja "privado, discreto e seguro": um "lar, doce lar” (BRASIL, 2011, p. 133). Esse espaço que se propõe criar é um lugar físico onde os jovens se encontram com regularidade, onde podem "agir naturalmente como gays sem se preocupar", "sem se preocupar que pessoas incomodadas com a orientação sexual deles os perturbem" (p. 135). A afirmação de que "os níveis de relações sexuais desprotegidas entre jovens HSH estão aumentando" (p. 22) justifica a afixação de cartazes e materiais informativos sobre prevenção ao HIV/ Aids no local, pois assim "jovens que estão simplesmente passando um tempo no espaço [...] recebem uma mensagem contínua sobre essas questôes” (p. 136). Isso caracteriza a criação de uma comunidade particular em que a dupla noção de risco participa na circunscrição das atividades relacionadas à metodologia.

Tais comunidades particulares são incitadas a tomar a responsabilidade pela consciência do seu (assim chamado) risco, levá-lo a sério e, a partir dele e em função dele, adotar práticas concretas e conscientes para evitá-lo. A formação de comunidades responsáveis se caracteriza pela participação de indivíduos também responsáveis, que se engajam (ou são chamados a se engajar) em um processo de identificação com tais comunidades (MILLER; ROSE, 2008). Na formação e preservação das comunidades responsáveis, 
[o] sujeito é dito como um indivíduo moral com laços de obrigação e responsabilidade pela conduta que são arranjados em um novo modo - o indivíduo na sua comunidade é tanto autorresponsável quanto sujeito de certos laços emocionais de afinidade de uma rede circunscrita de outros indivíduos unidos por laços familiares, de localidade [e de sexualidade]. A conduta é resgatada de uma determinação pela ordem social e é colocada em uma nova percepção ética do ator individualizado e autonomizado, em que cada um tem laços únicos, localizados e específicos em relação a uma família em particular e a uma comunidade moral (MILLER; ROSE, 2008, p. 91, acréscimo nosso).

A formação de comunidades responsáveis é um dos elementos centrais para as tecnologias de governamento na atualidade, especialmente no campo da saúde pública (MILLER; ROSE, 2008; LUPTON, 1995). Na emergência de comunidades responsáveis, "vetores e forças puderam ser mobilizados, arrolados, empregados em novos programas e técnicas que operaram através da instrumentalização de alianças pessoais e responsabilidades ativas" que objetivaram "o governamento através da comunidade" (MILLER; ROSE, 2008, p. 89-90, grifo dos autores). Criando uma comunidade responsável e autônoma, em que cada participante regula sua própria conduta e também a conduta dos demais em relação ao risco - de contrair doenças, desenvolver agravos de saúde, expor-se à violência, etc. -, o Estado pode se abster de fazê-lo em dadas direções.

É fulcral entender aqui que, para Miller e Rose (2008), a concepção de governamento refere-se à possibilidade de intervenção na realidade e intervenção direta em grupos separados de acordo com seu nível de risco, segundo Lupton (1999). Espera-se que eles próprios "tomem o controle para prevenir o risco através de suas próprias açōes” (LUPTON, 1999, p. 100). As intervenções na realidade de cada comunidade responsável, circunscrita pelo seu risco, devem ser constantemente medidas e feitas calculáveis através de diferentes métodos de exame e escrutínio, entre os quais destacamos:

técnicas de registro, computação e cálculo; procedimentos de exame e avaliação; a invenção de instrumentos como surveys e formas de apresentação como tabelas; padronização de sistemas de treinamento e a inculcação de hábitos; [...] modelo de prédios e formas arquiteturais (MILLER; ROSE, 2008, p. 32).

Encontram-se tais técnicas de medição, cálculo e sistematização no interior da metodologia MPowerment quando o manual menciona como fundamental uma etapa prévia de "mapeamento da comunidade" de jovens gays e bissexuais, com o objetivo de "obter um entendimento abrangente da comunidade", criando um 
“'mapa' da vivência dos jovens” e procurando saber "como a comunidade tem respondido à crise da Aids” (BRASIL, 2011, p. 45). É a partir de tecnologias de "mapeamento da comunidade", como entrevistas, grupos focais e anotaçôes de observações dos espaços de sociabilidade já existentes que se vai, depois, “determinar como criar um programa de prevenção ao HIV que vai funcionar” (p. 45).

O desenho desse "mapa de vivências" prévio serve para construir a própria noção de comunidade em que a metodologia se propõe a intervir, bem como identificar meios de arregimentar jovens para, desde aí, serem empoderados na prevenção ao HIV/Aids. O "mapeamento da comunidade" supõe uma comunidade pré-existente sobre a qual se vai intervir para formar uma comunidade derivada, diferenciada, responsável pela promoção da saúde, de práticas de sexo seguro, empoderada para a prevenção ao HIV/Aids. Portanto, trata-se de uma comunidade inventada, construída pelo próprio discurso que lhe dá origem, que não necessariamente se efetiva em uma comunidade real de apoio e sustentação de princípios voltados à prevenção.

O mapeamento prévio está associado, sobretudo, a diversos procedimentos de "monitoramento e avaliação da eficácia das atividades" (BRASIL, 2011, p. 267-323). Destacamos a relevância da avaliação no sentido de apontar se as propostas de intervenção estão "promovendo o sexo mais seguro, construindo uma comunidade saudável e empoderando os voluntários" e ajudar a "estabelecer o planejamento mais eficiente de programas [de prevenção], ao eliminar a maior parte das conjecturas, substituindo-as por dados concretos" (p. 269). Isso significa que os dados produzidos pelo "mapeamento da comunidade" serão comparados àqueles produzidos pelos instrumentos de monitoramento e avaliação das atividades da metodologia no sentido de medir, demonstrar e verificar, sem "conjecturas" e a partir de "dados concretos", o sucesso ou fracasso das intervenções de prevenção.

Assim, podemos pensar que esses procedimentos visam a tornar uma conduta - práticas sexuais de jovens gays e bissexuais consideradas de risco passível de intervenção - empoderamento dos jovens para a prevenção, no sentido de diminuir o risco de infecção pelo HIV -, na qual se parte de técnicas e instrumentos que permitem que uma realidade seja medida para, em seguida, ser transformada em uma determinada direção (MILLER; ROSE, 2008). Por isso, o monitoramento e a avaliação das atividades propostas pela metodologia 
são tão importantes: não apenas permitem aferir sucesso à implementação, mas, sobretudo, possibilitam a identificação de seus fracassos. A identificação de dificuldades servirá para o aprimoramento da experiência de empoderamento, na medida em que o "fracasso" em atingir algum objetivo é inerente aos procedimentos de intervenção nas condutas, porque dele vão se derivar mudanças nas atividades com o intuito de melhorá-las, aprimorá-las, torná-las mais eficazes no governamento da conduta (MILLER; ROSE, 2008).

Tal identificação necessita ser objetiva, "concreta", livre de "conjecturas". $\mathrm{O}$ manual sugere a aplicação periódica entre os jovens da comunidade de questionários a partir dos quais se vão gerar escalas de "atitude sobre o prazer", "autoeficácia sexual" e "frequência com que o indivíduo incentiva amigos a praticarem sexo seguro” (BRASIL, 2011, p. 323), além daquelas que pretendem medir a "homofobia internalizada" e o uso/abuso de álcool e outras drogas, derivando daí a "pontuação média” obtida por cada indivíduo para cada escala (p. 325-326). Portanto, o empoderamento dos jovens gays e bissexuais precisa ser avaliável, monitorável, individualizável, autonomizável, porque “a avaliação de resultados ajudará a determinar se o projeto contribuiu para mudar os conhecimentos, atitudes, convicções e/ou comportamentos de jovens que participam" da metodologia (p. 271).

A criação dessa comunidade responsável de jovens gays e bissexuais conscientes dos riscos que correm na infecção pelo HIV e autorregulados na direção de praticar sexo mais seguro faz parte da mobilização e intervenção amplas e complexas que o manual propõe para a implementação do conceito-estratégia de empoderamento. É dentro de uma racionalidade de governamento - entendida como a "forma de representar e conhecer um fenômeno", enquanto "os campos discursivos mutantes dentro dos quais o exercício de poder é conceitualizado, justificações morais para modos particulares de exercício de poder" - que se propóem uma série de tecnologias de governamento entendidas como "um modo de agir sobre [o fenômeno] para transformá-lo", como "o complexo de programas, cálculos, técnicas, dispositivos, documentos e procedimentos mundanos através dos quais [...] incorpora-se e dá-se efeito às ambições do governamento" (MILLER; ROSE, 2008, p. 15; p. 55).

$\mathrm{O}$ empoderamento, portanto, age intervindo nas condutas, nos comportamentos, na regulação dos corpos, na gestão da vida dos indivíduos que participam da comunidade. Tal intervenção tem determinados objetivos, 
que precisam estar constantemente sob escrutínio. Nessa racionalidade de governamento, "a comunidade é feita calculável por toda uma variedade de relatórios, investigações, inquéritos estatísticos, é a premissa e o objetivo de uma série de tecnologias de governamento" (MILLER; ROSE, 2008, p. 111). Para que se governe nas e através das comunidades, é preciso torná-las governáveis, assim como também é preciso tornar governáveis os indivíduos que dela farão parte. $\mathrm{Na}$ metodologia MPowerment, o governamento se dá a partir de uma racionalidade (saberes, conhecimentos, informações e discursos criados a partir da investigação minuciosa da comunidade) e de tecnologias (proposição de atividades e posterior emprego de métodos de monitoramento e avaliação da comunidade), ambas articuladas pelo conceito-estratégia de empoderamento.

\section{Assinalando limites e perigos}

O empoderamento proposto pela metodologia MPowerment acena para a construção de uma comunidade responsável e autogovernada de jovens gays e bissexuais, em que cada participante é empoderado na direção de constituir para si e para o grupo uma autonomia regulada por uma série de medidas e cálculos baseados no seu risco de infecção pelo HIV. O empoderamento do qual se fala aqui não é qualquer empoderamento. Tampouco não é qualquer liberdade que se pretende construir ao forjar essa comunidade. "Apenas um certo tipo de liberdade - um certo modo de entender e exercer a liberdade, de relacionarmo-nos individual e coletivamente como sujeitos de liberdade" (ROSE, 1999, p. 63) - se encaixa nesse modelo explicado passo a passo e que ganha formato de manual de treinamento. "O governamento da liberdade [...] pode ser analisado em termos do emprego de tecnologias da responsabilização" (ROSE, 1999, p. 74, grifo do autor).

Nesse processo, os jovens ganham um espaço onde "eles podem ser eles mesmos" (BRASIL, 2011, p. 262), mas ainda assim estão na "obrigação de permanecerem saudáveis" (ROSE, 1999, p. 255). A liberdade, o autocuidado, o cuidado com os demais integrantes da comunidade, são regulados pelo imperativo do sexo seguro sem que se explorem ou que se problematizem os desejos e prazeres da transgressão desse imperativo, por exemplo (LUPTON, 1995). Para cada asseveração regulatória, para cada investimento na tentativa de afastar os indivíduos do risco, produz-se simultaneamente uma "crescente fascinação com os prazeres e excitações em correr riscos” (LUPTON, 1999, p. 151). 
O jovem que decide, por inúmeras razões, engajar-se no sexo inseguro - leiase, aquele não preconizado pela prevenção - será imediatamente designado como um jovem “desempoderado". A concepção de "desempoderamento" só existe no seio de uma racionalidade de empoderamento no qual o poder é tido como um atributo, algo que se tem ou detém. Daí a facilidade em designar alguém que não segue as prescrições do sexo seguro como "desempoderado": esse indivíduo é tido como alguém que precisa ser alvo de uma intervenção que visa à transferência ou criação de poder para que ele(a) possa decidir o que é melhor para si. Mas a definição daquilo que é "melhor" nunca é ele(a) quem constrói sozinho(a): é-lhe dada pronta, baseada em imperativos como "faça sexo seguro". "De fato, o empowerment é frequentemente usado para disfarçar a função de controle social de profissionais da saúde que visam a populações com conceitos pré-formulados", que geralmente ganham forma em "diretrizes para elaboração e avaliação de ações" (FERREIRA; CASTIEL, 2009, p. 70).

Por outro lado, se concebermos poder como uma relação e um exercício do qual participam múltiplos vetores e que depende da presença de resistência contra ele para que seja exercido, entendemos que o poder ganha sua forma na medida em que relações são estabelecidas entre indivíduos livres (FOUCAULT, 2012; 1995). Somente na existência, mesmo que virtual, de resistência e liberdade é que pode haver relações de poder sem que elas sejam concebidas como "transferência externa, altruística, como se [o poder] fosse uma entidade, uma coisa" (FERREIRA; CASTIEL, 2009, p. 70) que vai de um polo "empoderado" a outro “desempoderado". Daí que não há ninguém totalmente “desempoderado"; pelo contrário, há virtualmente a possibilidade de exercício de poder em qualquer relação, por parte de qualquer um dos envolvidos. É precisamente na imanência das relações de poder que ele é exercido - e não transferido ou simplesmente criado em pessoas ou grupo de pessoas onde antes ele supostamente não existia.

Da mesma forma, não há exercício de poder sem resistência, sem a real ou virtual prática de liberdade. $\mathrm{O}$ perigo que enfatizamos é que algumas práticas que nos são apresentadas como sendo liberdade, como o faz o empoderamento, funcionam no interior de racionalidades e tecnologias de governamento que colonizam a liberdade a ponto de fazê-la funcionar a favor da regulação dos indivíduos. Ainda, a autonomia regulada desses indivíduos circunscritos em comunidades responsáveis favorece, como princípio e fim pressupostos em tal 
racionalidade, a desobrigação do Estado para com eles, uma vez que, estando cientes de seus riscos e tomando as providências que lhes são cabíveis como indivíduos também responsáveis - ou seja, estando empoderados -, o papel e os gastos do Estado em prover assistência para esses indivíduos podem sutilmente sair da agenda política (ROSE, 1999).

$\mathrm{Na}$ medida em que a "liberdade é um artefato do governamento" (ROSE, 1999, p. 63), é também preocupante operarmos com noções de empoderamento na prevenção ao HIV/Aids, nas quais liberdade é tida como sinônimo de autonomia, tomada de consciência e autocuidado. Isso porque justamente o que está em jogo em formulações como essas é a produção de autonomias reguladas, em que a "consciência" que se busca dar é sempre uma determinada consciência já previamente formada, propiciando escolhas "livres" apenas dentre opçôes previamente dadas. Carvalho e Gastaldo (2008, p. 2035) destacam que

é importante, portanto, estarmos atentos para que possamos questionar e refletir sobre a verdade e o discurso que a sustenta. Ser reconhecido como pessoa sadia, reflexiva, comprometida, responsável, emocional e cognitivamente generosa é efeito do empoderamento ou de uma lógica de autogoverno sofisticada?

Assim, a liberdade e o empoderamento sobre os quais versa a metodologia apontam para uma única direção: "o reforço contínuo de normas relativas ao sexo seguro” (BRASIL, 2011, p. 25), conforme o manual. Nesse contexto, o conceitoestratégia de empoderamento não atende satisfatoriamente às demandas sociais ou programáticas implicadas na prevenção ao HIV/Aids entre a população de jovens gays e bissexuais.

Consideremos, hipoteticamente, um jovem gay ou bissexual tido como empoderado, que busca preservativos gratuitos em um posto de saúde e não tem acesso a eles porque um profissional de saúde o julga muito jovem para tê-lo. Consideremos um jovem que se empodera o suficiente para contar aos pais que é gay ou bissexual e que, por isso, sofre algum tipo de violência ou repressão no ambiente doméstico. Ainda podemos pensar em um jovem gay ou bissexual que fala sobre sua soropositividade para outros jovens afirmando sua cidadania e sexualidade como soropositivo. Não poderia ele ser considerado um jovem empoderado?

Um jovem gay ou bissexual que escolhe "livremente" usar preservativos apenas com parceiros eventuais, mas que com seu (sua) parceiro(a) estável prescinde do uso de camisinha devido a um pacto entre ambos, baseado no 
ideal de amor romântico; esse jovem é um empoderado e, ao mesmo tempo, um "desempoderado"? Empodera-se alguém, ou uma comunidade, de uma vez por todas e para sempre? Ao mencionarmos essas perguntas, além de colocarmos em xeque o potencial empírico e político do empoderamento, também apontamos para a criação de novos limiares de inclusão e novos mecanismos de exclusão no seio da operacionalização dessa metodologia. Assim, Rose (1999, p. 259) sugere:

Parece que fora das comunidades de inclusão existe um impressionante número de microssetores, microculturas de não cidadãos, cidadãos falhos, anticidadãos, que consistem daqueles que são inábeis ou relutantes de gerenciar suas vidas e administrar seu próprio risco, incapazes de exercer o autogovernamento responsável, ligados tanto a uma comunidade sem moral ou a uma comunidade da antimoralidade.

Com esses exemplos, talvez não tão hipotéticos, buscamos aludir à insuficiência do conceito-estratégia de empoderamento no que tange às dimensões sociais, políticas e programáticas dentro das quais a população de jovens gays e bissexuais se encontra. Essa insuficiência sugere que o empoderamento, enquanto conceito exclusivo e estrito de metodologias de prevenção ao HIV/Aids, deve ser associado a outros conceitos dos quais derivam outras estratégias que deem conta de aspectos mais amplos que o empoderamento não alcança - pelo menos não do modo como abordado no manual MPowerment. A exclusividade do empoderamento como conceito-estratégia norteador de metodologias de prevenção produz não apenas sujeitos empoderados (supostamente livres e autônomos), mas também uma densa população de sujeitos doravante considerados desempoderados, isto é, estultos, fracos, irresponsáveis com sua saúde e com a dos demais - e que serão invariavelmente alvo de reiteradas ações de conscientização.

\section{Considerações finais: quando o empoderamento enfraquece}

Há muito tempo, a resposta brasileira à epidemia de HIV/Aids vem adotando como referência o paradigma dos Direitos Humanos, o que conferiu um caráter profundamente político na construção de práticas preventivas entre os grupos afetados (GALVÃO, 2000; PARKER, 2000, 1994). Esse viés faz com que tais estratégias associem inextricavelmente a prevenção do HIV ao exercício de cidadania. Também defende a garantia de acesso universal à saúde e à assistência como direito humano e como parte inerente do processo de prevenção (PAIVA, 2009; BECKER et al., 2004). 
Conforme argumentamos, a metodologia MPowerment e o conceito-estratégia que emprega não se relacionam com a resposta brasileira à epidemia de Aids, que tem como características a valorização do acesso universal dos serviços oferecidos pelo Estado a todos os cidadãos. Sua inserção no Brasil, como se apresenta, precisa ser revista cuidadosa e criticamente, não apenas para adaptar-se ao contexto brasileiro, mas para que possamos verificar se já não houve outrora experiências em prevenção similares e mais consonantes com nossa realidade política e cultural.

Conforme já mostramos, houve importantes trajetórias consolidadas de desenvolvimento de estratégias de prevenção e promoção da saúde entre a população de HSH e gays no Brasil, além de já existirem Planos Nacionais que oferecem uma agenda de ações no campo da saúde voltada para essa população específica. Sublinhamos que essa agenda de ações preventivas foi construída em diálogo com os movimentos sociais, algo que reitera a marca democrática do processo. Um conceito único e exclusivo que sirva de referência para uma intervenção massiva em uma dada população, como se pretende o MPowerment, tende a desconsiderar não apenas a tradição da resposta brasileira à epidemia de HIV/Aids, mas também a multiplicidade na qual se inscrevem as vidas dos jovens gays e bissexuais a quem se dirige.

Assim, reiteramos que, do modo como está apresentado, o empoderamento proposto por essa metodologia serve como tecnologia de regulação das autonomias e dos corpos da população que pretende atingir, servindo como vetor sutil de governamento da vida de jovens gays e bissexuais. $\mathrm{O}$ empoderamento que preconiza é unidirecional, calculável, mensurável, associado diretamente a uma estratégia de responsabilização individual - algo que vai na contramão da tradição brasileira de prevenção à Aids. O empoderamento do qual o manual fala é insuficiente para dar conta de situações complexas com as quais a prevenção precisa lidar, sem considerar que o reforço do imperativo do sexo seguro pode produzir resistências, como o fascínio pela sua transgressão (LUPTON, 1995).

A dificuldade da tradução de "empowerment" não é apenas linguística; é uma dificuldade sobretudo política, posto que a inserção desse conceito-estratégia como norteador de políticas públicas de prevenção (como parece ao ser publicado na página oficial do Ministério da Saúde do Brasil) deve ser articulada à longa experiência em pesquisa, prática e militância na resposta à epidemia de HIV/Aids que o Brasil acumula até hoje ${ }^{8}$. 


\section{Referências}

AYRES, J.R.C. et al. Vulnerabilidade e prevenção em tempos de Aids. In: BARBOSA, R.M., PARKER, R. (Orgs.) Sexualidades pelo avesso. São Paulo: Editora 34, 2000. p. 49-73. BECKER, D. et al. Empowerment e avaliação participativa em um programa de desenvolvimento local e promoção da saúde. Ciência \& Saúde Coletiva, v.9, n.3, p.655667, 2004.

BELOQUI, J. Risco relativo para Aids de homens homo/bissexuais em relação aos heterossexuais. Rev. Saúde Pública, v.42, n.3, p.437-42, 2008.

BRASIL. Ministério da Saúde. Plano Nacional de Enfrentamento À Epidemia de Aids e das DST entre Gays, HSH e Travestis. Brasília: Ministério da Saúde. 2007. Disponível em < http://bvsms.saude.gov.br/bvs/publicacoes/plano_enfrentamento_epidemia_aids_hsh. pdf> Acesso em: 25 maio 2013.

BRASIL. Ministério da Saúde. DEBI Brasil MPOWERMENT Estratégia de Prevenção para as DST-HIV. Brasília: Ministério da Saúde, 2011. Disponível em <http:/www.aids.gov. $\mathrm{br} /$ sites/default/files/anexos/publicacao/2011/50346/manual_mpowerment_74254.pdf>. Acesso em: 02 maio 2012.

CARVALHO, S.R. Promoción de la Salud, “empowerment” y educación: una reflexión crítica como contribución a la reforma sanitária. Salud Colectiva, Buenos Aires, n.3, p.335-347, 2008.

As contradições da promoção à saúde em relação à produção de sujeitos e a mudança social. Ciência \& Saúde Coletiva, v.9, n.3, p.669-678, 2004 b.

. Os múltiplos sentidos da categoria "empowerment" no projeto de Promoção à Saúde. Cad. Saúde Pública, Rio de Janeiro, v.20, n.4, p.1088-1095, $2004 a$.

CARVALHO, S.R.; GASTALDO, D. Promoção à saúde e empoderamento: uma reflexão a partir das perspectivas crítico-social e pós-estruturalista. Ciência \& Saúde Coletiva, v.13, sup 2, p.2029-2040, 2008.

FERREIRA, M.S.; CASTIEL, L.D. Which empowerment, which Health Promotion? Conceptual convergences and divergences in preventive health practices. Cad. Saude Pública, Rio de Janeiro, v.25, n.1, p.68-76, 2009.

FOUCAULT, M. História da sexualidade: a vontade de saber. Rio de Janeiro: Graal, 2012. , O sujeito e o poder. In: DREYFUS, H.; RABINOW, P. (Orgs.). Michel Foucault: uma trajetória filosófica. São Paulo: Forense Universitária. 1995. p.231-249.

Microfísica do Poder. Rio de Janeiro: Graal, 1984.

GALVÃO, J. Aids no Brasil: a agenda da construção de uma epidemia. São Paulo: Editora 34, 2000. 259 p. 
KEGELES, S.M.; HAYS, R.B.; COATES, T.J. The MPowerment Project: A Community-

Level HIV Prevention Intervention for Young Gay Men. American Journal of Public Health, v.86, n.8, p.1129-1136. 1996.

LAVERACK, G.; LABONTE, R. A planning framework for community empowerment goals within health promotion. Health Policy Plan, v.15, n.3, p.255-262. 2000.

LAVERACK G.; WALLERSTEIN, N. Measuring community empowerment: a fresh look at organizational domains. Health Promotion International, v.16, p.179-85. 2001.

LEFÉVRE, F.; LEFÉVRE, A.M.C. Saúde, empoderamento e triangulação. Saúde Soc., v.13, n.2, p.32-38, 2004.

LUPTON, D. The imperative of Health: public health and the regulated body. London: Sage, $1995.181 \mathrm{p}$.

. Risk. New York: Routlegde, 1999. 184 p.

MARQUES JR, J.S.; GOMES, R.; NASCIMENTO, E.F. Masculinidade hegemônica, vulnerabilidade e prevenção ao HIV/AIDS. Ciência \& Saúde Coletiva, v.17, n.2, p.511520. 2012.

MARTINS, P.C. et al. Democracia e empoderamento no contexto da promoção da saúde: possibilidades e desafios apresentados ao Programa de Saúde da Família. Physis: Revista de Saúde Coletiva, Rio de Janeiro, v.19, n.3, p.679-694, 2009.

MEYER, D.E.E. et al. "Você aprende. A gente ensina?” Interrogando relações entre educação e saúde desde a perspectiva da vulnerabilidade. Cad. Saúde Pública, Rio de Janeiro, v.22, n.6, p.1335-1342, 2006.

MILlER, P.; ROSE, N. Governing the Present. Cambridge: Polity Press, 2008. 245 p.

MYRICK, R. Aids, Communication and empowerment: gay male identity and the politics of Public Health Messages. New York: Harrington Park Press, 1996.

RIFKIN, S.B. A framework linking community empowerment and health equity: it is a matter of CHOICE. Journal of Health, Population and Nutrition, v.21, n.3, p.168-180, 2003. PAIVA, V. Sem mágicas soluçôes: a prevenção e o cuidado em HIV/ AIDS e o processo de emancipação psicossocial. Interface, Comunic. Saúde, Educ. v.6, n.11, p.25-38, 2002.

. Prevenção Posithiva? A abordagem psicossocial, emancipação e vulnerabilidade. In: RAXACH, J.C. et al. (Orgs). Prevenção posithiva: estado da arte. Rio de Janeiro: ABIA, 2009. p. 33-50 (Coleção Abia, políticas públicas 8).

PARKER, R. Empoderamento erótico e cidadania sexual para homens que fazem sexo com homens e tribos afins. In: RIOS, L.F. et al (Orgs.). Homossexualidade: produção cultural, cidadania e saúde. Rio de Janeiro: Abia, 2004. p. 11-16. 

. Na contramão da Aids: sexualidade, intervenção, política. Rio de Janeiro: Editora 34, 2000. $163 \mathrm{p}$. . A construção da solidariedade: Aids, sexualidade e política no Brasil. Rio de Janeiro: Relume Dumará, 1994. 141 p.

ROSE, N. Powers of freedom: reframing political thought. Cambridge: University Press, 1999. $321 \mathrm{p}$.

TULLOCH, J.; LUPTON, D. Risk and everyday life. London: Sage, 2003. 140 p.

\section{Notas}

${ }^{1}$ Declaramos que Luiz Felipe Zago atuou como coordenador do projeto-piloto de implantação da metodologia MPowerment, na cidade de Porto Alegre/RS, durante os meses de abril a setembro de 2011. O projeto-piloto foi financiado pelo Departamento Nacional de DST, Aids e Hepatites Virais do Ministério da Saúde, Escola Nacional de Saúde Pública Sérgio Arouca e Escritório Brasileiro do Centers For Disease Control dos Estados Unidos. Os autores declaram que, embora um de nós tenha sido remunerado pelo desempenho das funçães de coordenação pelo período de implementação do projeto-piloto por parte do consórcio institucional referido, não tivemos acesso a qualquer informação privilegiada para a escrita das análises aqui publicadas. As discussões apresentadas neste artigo são circunscritas aos materiais publicados no site do Ministério da Saúde, não contando com qualquer apoio de ordem financeira, pois o vínculo de um dos autores com o projeto-piloto e com o consórcio institucional extinguiu-se em novembro de 2011. Não obstante, reconhecemos que o envolvimento de um dos autores como integrante da equipe implementadora do projeto-piloto da metodologia aqui analisada é parte inseparável da postura crítico-problematizadora por nós adotada nas argumentações que seguem.

${ }^{2}$ Disponível em <http://www.effectiveinterventions.org/en/Home.aspx>, acessado em 26 de junho de 2013.

${ }^{3}$ Disponível em <http://www.cdc.gov/hiv/topics/msm/index.htm>, acessado em 26 de junho de 2013.

${ }^{4}$ O CDC mantém escritório junto ao Ministério da Saúde brasileiro desde 2003, segundo informação da página oficial do Departamento de Estado dos Estados Unidos da América. Disponível em <http:// iipdigital.usembassy.gov/st/portuguese/texttrans/2012/04/201204103535.html\#axzz2XEtjPwqz>, acessado em 26 de junho de 2013.

${ }^{5}$ Informaçōes publicadas no site do Ministério da Saúde. Disponível em <http://www.aids.gov.br/ pagina/debi-brasil>, acesso em 26 de junho de 2013.

${ }^{6}$ Susan Kegeles é codiretora do Center For AIDS Prevention Studies. Foi uma das criadoras da estratégia MPowerment nos Estados Unidos.

${ }^{7}$ As traduções das referências em língua estrangeira são de responsabilidade de ambos os autores.

${ }^{8}$ L.F. Zago participou da revisão de bibliografia e organização do argumento teórico. L.H.S. Santos participou da revisão conceitual. Os autores agradecem a Daniel Boianovsky Kveller e Maurício Nardi Vale pelas contribuiçóes críticas durante a escrita do texto. 
The limits of the concept of empowerment in HIVIAids prevention among young gay and bisexual men in Brazil

The paper seeks to analyze the limits of the concept of empowerment within HIV/Aids prevention among young gay and bisexual men in Brazil. It uses propositions of an official document of the Ministry of Health of Brazil, in form of a methodological handbook for prevention. It employs empowerment as the main theoretical and methodological tool to conduct prevention actions in this population, and the text develops a conceptual discussion on the possibilities for its implementation. The analysis draws on the post-structuralist framework to examine the ways through which the concept is described and used in the activities that are suggested by the manual. The analyses indicate that empowerment is a strategy that functions within a wide rationality of government of bodies and autonomies of the targeted individuals through their insertion in communities, for the concept becomes a technology of regulation of sexual practices and countable measurement of subjectivity. The analyses also explore notions of risk and accountability which circumscribe the community of young gay and bisexual men. Finally, the analyses underline the impasses that may be generated by the insertion of empowerment within the Brazilian HIV/Aids activism without previous critical review of the ways it is conceived and used.

> Key words: power; health promotion; public health practice; HIV/Aids. 